\title{
AUDIT KESELAMATAN JALAN TOL CIPALI
}

\author{
Felix Marco Surya ${ }^{1}$ dan Ni Luh Putu Shinta Eka Setyarini \\ ${ }^{1}$ Program Studi Sarjana Teknik Sipil, Fakultas Teknik, Universitas Tarumanagara \\ felix.marco31@yahoo.co.id \\ ${ }^{2}$ Program Studi Sarjana Teknik Sipil, Fakultas Teknik, Universitas Tarumanagara \\ shintarachmat@yahoo.com
}

\begin{abstract}
ABSTRAK
Sekarang ini jalan tol merupakan salah satu jalan bebas hambatan yang keberadaannya saat ini sangat dibutuhkan untuk mempercepat memperpendek waktu tempuh, hal ini akibat jalan arteri yang sudah ada semakin macet terutama pada saat jam - jam sibuk dan akhir pekan. Dengan semakin padatnya pengguna jalan tol membuat angka risiko kecelakaan mobil di jalan tol juga semakin meningkat. Salah satu penyebab kecelakaan kendaraan yang terjadi dijalan tol diakibatkan oleh kurangnya bangunan pelengkap dan perkerasan yang kurang baik.. Penelitian ini akan membahas persepsi perngemudi terhadap bangunan pelengkap seperti rambu serta marka dan juga dari segi perkerasan di jalan tol dengan menggunakan metode quisioner dengan wawancara langsung. Pengolahan data quisioner ini menggunakan metode analysis of variance (ANOVA) dibantu dengan program SPSS dan dibandingkan dengan hasil data kecelakaan dari kepolosian atau PU yang dapat membantu kita untuk mengetahui bagaimana persepsi pengemudi di jalan tol dalam keselamatan pengemudi dari segi bangunan pelengkap dan perkerasan di jalan tol. Hasil oberservasi secara langsung, kondisi eksisting geometrik, bangunan pelengkap, dan perkerasaan sudah cukup baik. Namun terdapat kekurangan rambu dan jalan yang tidak halus dalam perkerasaan di beberapa ruas jalan tol Cipali, akan tetapi tidak mempengaruhi kenyamanan pengemudi untuk pengguna jalan tol Cipali menurut wawancara pada saat penyebaran kusioner berlangsung.
\end{abstract}

Kata kunci : Jalan Tol, Bangunan Pelengkap, SPSS

\section{PENDAHULUAN}

Pada tahun 2015, sebanyak 47 proyek pembangunan jalan tol yang termasuk dalam Proyek Strategis Nasional oleh Presiden Republik Indonesia periode 2015-2019 mulai dilaksanakan. Bahkan Peraturan Presiden Republik Indonesia Nomor 3 Tahun 2016 dikeluarkan agar pelaksanaan Proyek Strategis Nasional tersebut dapat dipercepat. Mengingat Undang-Undang Republik Indonesia Nomor 38 tahun 2004 tentang jalan, pada Pasal 44 ayat 3 disebutkan bahwa jalan tol harus mempunyai spesifikasi dan pelayanan yang lebih tinggi daripada jalan umum yang ada, antara lain tidak ada persimpangan sebidang, jalan keluar atau jalan masuk (akses) dikendalikan secara penuh, dan kecepatan rencana tinggi.

Kekhawatiran menjadi muncul ketika pembangunan jalan terus berlanjut namun sistem keselamatan jalan masih belum maksimal dalam penerapannya. Terjadi kecelakaan sepanjang tahun 2016 lebih dari 26.000 orang meninggal dunia dan 143.000 mengalami luka ringan maupun berat maka pada Maret tahun 2010 Majelis Umum PBB mendeklarasikan Decade of Action (DoA) for Road Safety 2011 - 2020 yang bertujuan untuk mengendalikan dan mengurangi tingkat fatalitas korban kecelakaan lalu lintas jalan secara global dengan meningkatkan kegiatan yang dijalankan pada skala nasional, regional dan global.

Pada tahun 2016 tol Cipali mengalami jumlah kecelakaan sebanyak 811. Sesuai dengan strategi jangka panjang yang disusun oleh Pemerintah Indonesia dalam Rencana Umum Nasional Keselamatan (RUNK) Jalan, diperlukannya penyelenggaraan keselamatan jalan menggunakan pendekatan efisiensi biaya melalui tindakan kuratif dan preventif dalam rangka penanganan korban, pencegahan luka, dan pencegahan kecelakaan. Penelitian ini berusaha untuk menyelesaikan permasalahan keselamatan jalan yang terjadi pada jalan di Indonesia khususnya jalan tol karena pelayanan yang diberikan oleh jalan tol seharusnya lebih tinggi dibandingkan dengan jalan umum. Dalam mencegah kecelakaan, perlu diketahui area mana saja yang memiliki potensi tinggi untuk terjadi kecelakaan sehingga dapat ditangani sesuai dengan karakteristik jalannya masing-masing.

Jadi penelitian ini bertujuan untuk mengetahui kondisi eksisting geometrik, perkerasan, bangunan pelengkap jalan tol Cipali sudah sesuai terhadap standar teknis yang telah diterapkan, sehingga diperoleh daerah rawan kecelakaan pengamatan langsung. Lalu hasil daerah rawan kecelakaan pengamatan langsung dibandingkan dengan daerah 
rawan kecelakaan data sekunder yaitu data kecelakan lalu lintas. Dan hasil analisis daerah rawan kecelakaan dari pengematan langsung dan data kecelakaan lalu lintas dibandingkan dengan data dari kuisioner wawancara langsung dan online dengan metode statistik, untuk mengetahui apakah daerah rawan kecelakaan yang diperoleh dari ketiga data semuanya sama.

\section{Audit keselamatan jalan}

Audit Keselamatan Jalan adalah suatu bentuk pengujian formal suatu ruas jalan yang ada atau sebuah proyek jalan/lalulintas dimana sebuah tim yang independen dan berkualifikasi memberikan laporan mengenai potensi tabrakan pada proyek tersebut (Austroads, 2009, dalam Departemen Pekerjaan Umum, 2010 ). Audit keselamatan jalan merupakan salah satu cara untuk mencegah kecelakaan bagi yang sudah beroperasi atau jalan yang baru dibuka. Audit keselamatan jalan pada jalan baru perlu dilakukan pada semua pangkat jalan mulai dari perancangan, bentuk jalan, pembinaan dan operasi. Audit keselamatan jalan pada awalnya dikembangkan untuk jalan-jalan baru, akan tetapi semakin banyak digunakan untuk memeriksa dan meningkatkan keselamatan jalan yang ada.

\section{Kecepatan rencana}

Kecepatan rencana (VR), pada suatu ruas jalan adalah kecepatan yang dipilih sebagai dasar perencanaan geometrik jalan yang memungkinkan kendaraan-kendaraan bergerak dengan aman dan nyaman dalam kondisi cuaca yang cerah, lalu-lintas yang lengang, dan pengaruh samping jalan yang tidak berarti (Bina Marga, 2004). VR untuk masing masing fungsi jalan dapat ditetapkan dari Tabel 1

Tabel 1 Kecepatan Rencana

Sumber : Bina Marga, 2004

\begin{tabular}{llll}
\hline Kelas & Fungsi & \multicolumn{2}{l}{ Kecepatan Rencana } \\
\cline { 3 - 4 } & & Primer & Sekunder \\
\hline I & Arteri primer & $80-100$ & - \\
\hline II & Kolektor primer & $80-100$ & $60-70$ \\
\hline IIIA & Arteri sekunder & $80-100$ & $60-70$ \\
\hline IIIB & Kolektor sekunder & 80 & 50 \\
\hline IIIC & Lokal sekunder & 60 & 40 \\
\hline
\end{tabular}

\section{Alinemen jalan}

Alinemen jalan merupakan faktor utama untuk menentukan tingkat aman dan efisien di dalam memenuhi kebutuhan lalulintas. Alinemen di pengaruhi oleh topografi, karakteristik lalulintas dan fungsi jalan.

\section{Marka jalan}

Suatu tanda yang berada di permukaan jalan atau di atas permukaan jalan yang meliputi peralatan atau tanda yang membentuk garis membujur, garis melintang, garis serong serta lambang lainnya yang berfungsi untuk mengarahkan arus lalulintas dan membatasi daerah kepentingan lalulintas.

\section{Rambu-rambu lalu lintas}

Rambu merupakan alat yang utama dalam mengatur, memberi peringatan dan mengarahkan lalulintas. Rambu yang efektif harus memenuhi hal-hal berikut:

1. Memenuhi kebutuhan

2. Menarik perhatian dan mendapat respek pengguna jalan.

3. Memberikan pesan yang sederhana dan mudah di mengerti.

4. Menyediakan waktu cukup kepada pengguna jalan dalam memberikan respon.

\section{Median jalan}

Pada arus lalu lintas yang tinggi seringkali dibutuhkan median guna memisahkan arus lalu lintas yang berlawanan arah. Jadi median adalah jalur yang terletak ditengah jalan untuk membagi jalan dalam masing - masing arah.

Secara garis besar median berfungsi sebagai:

1. Menyediakan daerah netral yang cukup lebar dimana pengemudi masih dapat mengontrol kendaraannya pada saat-saat darurat.

2. Menyediakan jarak yang cukup untuk membatasi / mengurangi kesilauan terhadap lampu besar dari kendaraan yang berlawanan arah.

3. Menambah rasa kelegahan, kenyamanan dan keindahan bagi setiap pengemudi.

4. mengamankan kebebasan samping dari masing-masing arah arus lalu-lintas. 


\section{Perkerasan jalan}

Permukaan tanah pada umumnya tidak mampu menahan beban kendaraan diatasnya sehingga diperlukan suatu konstruksi yang dapat menahan dan mendistribusikan beban lalu lintas yang diterimanya. Teknologi pembuatan terus berkembang sehingga sampai saat ini orang mencampur terlebih dahulu antara batuan dan aspal kemudian dihamparkan dan dipadatkan. Dengan campuran ini didapatkan campuran yang padat dan memiliki stabilitas yang tinggi.

Pada struktur perkerasan lentur, beban lalu lintas didistribusikan ke tanah dasar secara berjenjang dan berlapis. Dengan sistem ini beban lalu lintas didistribusikan dari lapisan permukaan ke lapisan di bawahnya. Lapisan yang tebal akan mendistribusikan beban lebih lebar pada lapisan dibawahnya demikian juga lapisan yang mutunya baik yang dinyatakan dengan nilai CBR sehingga akhirnya tekanan dari beban kendaraan diterima oleh tanah dasar menjadi kecil.

\section{METODOLOGI PENELITIAN}

\section{Metode pengumpulan data}

Metode survei dengan observasi lapangan dilakukan di lokasi yang sudah ditentukan. Data primer didapat melalui observasi langsung dan melakukan wawancara. Dalam penelitian ini adalah survei pada lokasi yang ditentukan dalam berbagai macam aspek, yakni geometrik belok kiri dan belok kanan, perkerasan jalan, bangunan pelengkap, dan bangunan penunjang yaitu dijalan tol Cipali. Untuk wawancara kita sudah menentukan indikator - indikator untuk pembuatan kusioner.

\section{Metode analisis data}

1. Metode observasi lapangan

Untuk observasi lapangan dilakukan perbandingan Antara kondisi eksisting jalan tol Cipali dari segi geometrik, pekererasan dan bangunan pelengkap jalan terhadap standar teknis.

\section{Metode analisis data}

Metode analisis data yang digunakan untuk penyebaran kusioner penelitian ini adalah dengan menggunakan program SPSS kemudian, dilakukan dengan cara uji sample F-test. Uji F dikenal dengan Uji serentak atau uji Model / Uji Anova, yaitu uji untuk melihat bagaimanakah pengaruh semua variabel bebasnya secara bersama-sama terhadap variabel terikatnya. Atau untuk menguji apakah model regresi yang kita buat baik/signifikan atau tidak baik/non signifikan. Uji F dapat dilakukan dengan membandingkan $\mathrm{F}$ hitung dengan Tabel $\mathrm{F}$, jika $\mathrm{F}$ hitung $>$ dari $\mathrm{F}$ tabel, (H0 di tolak H1 diterima) maka model signifikan atau bisa dilihat dalam kolom signifikansi pada Anova (Olahan dengan SPSS, Gunakan Uji Regresi dengan Metode Enter / Full Model). Model signifikan selama kolom signifikansi (\%) < Alpha (kesiapan berbuat salah tipe 1, yang menentukan peneliti sendiri, ilmu sosial biasanya paling besar alpha $10 \%$, atau 5\% atau $1 \%$ ). Dan sebaliknya jika F hitung < F tabel, maka model tidak signifikan, hal ini juga ditandai nilai kolom signifikansi (\%) akan lebih besar dari alpha. Dalam penelitian komparasional yang melakukan pembandingan antar mean satu atau dua sampel, yaitu apakah memang secara signifikan mean satu atau dua sampel yang diperbandingkan atau dicari perbedaannya itu memang berbeda, ataukah perbedaan itu terjadi karena kebetulan saja (by change) dapat menggunakan Uji-F atau F-Test dan Chi Kuadrat (Chi Square). Uji-F atau F-Test adalah salah satu test statistik yang dipergunakan untuk menguji kebenaran atau kepalsuan hipotesis nol/nihil (Ho) yang menyatakan bahwa di antara dua buah mean sampel yang diambil secara random dari populasi yang sama tidak terdapat perbedaan yang signifikan.

3. Metode equivalent accident number (EAN)

Daerah rawan kecelakaan lalu lintas adalah daerah yang mempunyai jumlah kecelakaan lalu lintas tinggi, resiko dan kecelakaan tinggi pada suatu ruas jalan (Warpani, 1999). Teknik pemeringkatan lokasi kecelakaan dapat dilakukan dengan pendekatan tingkat kecelakaan dan statistik kendali mutu (quality control statistic), atau pembobotan berdasarkan nilai kecelakaan (Pedoman Penanganan Lokasi Rawan Kecelakaan Lalu Lintas, 2004).

Salah satu metode untuk menghitung angka kecelakaan adalah dengan menggunakan metode EAN (Equivalent Accident Number) (Pignataro, 1973), yang merupakan pembobotan angka ekivalen kecelakaan mengacu pada biaya kecelakaan lalu lintas.

EAN dihitung dengan menjumlahkan kejadian kecelakaan pada setiap kilometer panjang jalan kemudian dikalikan dengan nilai bobot sesuai tingkat keparahan. Nilai bobot standar yang digunakan adalah Meninggal dunia (MD) = 12 , Luka berat $(\mathrm{LB})=3$, Luka ringan $(\mathrm{LR})=3$ (Soemitro, 2005). 
Rumus EAN:

$$
\mathrm{EAN}=12 \mathrm{MD}+3 \mathrm{LB}+3 \mathrm{LR}
$$

Penentuan lokasi rawan kecelakaan dilakukan berdasarkan angka kecelakaan tiap kilometer jalan yang memiliki nilai bobot EAN melebihi nilai batas tertentu. Nilai batas ini dapat dihitung antara lain dengan menggunakan metode Batas Kontrol Atas (BKA) dan Upper Control Limit (UCL).

Nilai Batas Kontrol Atas (BKA) ditentukan dengan menggunakan persamaan berikut:

dengan $\mathrm{C}=$ Rata-rata angka kecelakaan EAN

$$
\mathrm{BKA}=\mathrm{C}+3 \sqrt{\mathrm{C}}
$$

Nilai UCL (Upper Control Limit) ditentukan dengan menggunakan persamaan berikut:

$$
\mathrm{UCL}=\lambda+\psi \times \sqrt{ }([(\lambda / \mathrm{m})+((0.829) \mathrm{m})+(1 / 2 \times \mathrm{m})]
$$

dengan $\lambda=$ Rata-rata angka kecelakaan EAN, $\Psi=$ Faktor probabilitas $=2.576$ dan $\mathrm{m}=$ Angka kecelakaan ruas yang ditinjau (EAN)

\section{ANALISIS DAN PEMBAHASAN}

\section{Pengumpulan data}

Data-data yang diperoleh dari kuesioner responden yang disebar kepada pengguna rest area di KM 166 arah ke Cirebon dan KM 101 arah ke Jakarta Tol Cipali, rest area ini dipilih dikarenakan rest area tersebut merupakan rest area tipe A dan data aspek transportasi yang disurvei langsung di lapangan. Data responden yang diambil sebanyak 100 orang. Data responden didapatkan dengan penyebaran kuisioner secara langsung di rest area KM 166 dan KM 101 Tol Cipali sebanyak 50 orang dan melalui internet sebanyak 50 orang.

Data aspek transportasi yang disurvei dilapangan adalah bagaimana kondisi perkerasan jalan tol Cipali dan juga keadaan rambu, marka jalan, dan geometrik. Survei ini menggunakan kamera gopro untuk mendapatkan hasil video, yang kemudian akan diteliti dan diperhatikan lebih lagi untuk mendapatkan daerah rawan kecelakaan berdasarkan kondisi perkerasan jalan, rambu, dan marka.

\section{Kompilasi data}

Data diambil dengan menggunakan kuesioner secara langsung dan online dengan total sebanyak 100 responden. Analisis ini dimulai dengan memberikan gambaran umum mengenai data responden menggunakan Microsoft Excel untuk membuat chart ,kemudian dilanjutkan dengan menampilkan Pie Chart untuk menentukan persepsi pengemudi terhadap kondisi jalan Tol Cipali menggunakan Microsoft Excel lalu hasilnya kemudian dikelompokan sesuai geometrik jalan dan alinyemen jalan untuk setiap penilaian yang dipilih oleh responden.

\section{Data karateristik jalan}

Dari data karakteristik jalan kita dapat mengetahui kondisi keadaan bangunan pelengkap sekarang digunakan di ruas tol Cipali dan bagaimana keadaan geometrik dan perkerasan jalannya setiap kilometernya. Data karakteristik jalan

\begin{tabular}{|c|c|c|c|c|}
\hline KM & Kondisi Jalan & Kondisi Perkerasan & Rambu & Marka \\
\hline $75.4-93.0$ & Lurus & $\begin{array}{l}\text { Jalan sudah rata } \\
\text { dan halus }\end{array}$ & Tidak ada & $\begin{array}{l}\text { Marka } \\
\text { Membujur }\end{array}$ \\
\hline \multirow[t]{2}{*}{$85.2-86.0$} & Lurus & $\begin{array}{l}\text { Jalan tidak rata dan } \\
\text { bergelombang }\end{array}$ & Rest Area & $\begin{array}{l}\text { Marka } \\
\text { Membujur }\end{array}$ \\
\hline & & & $\begin{array}{l}\text { Batas minimum kecepatan } 60 \\
\mathrm{Km} / \mathrm{Jam} \& \text { batas maksimum } \\
\text { kecepatan } 100 \mathrm{Km} / \mathrm{Jam}\end{array}$ & \\
\hline $104.6-105.0$ & $\begin{array}{l}\text { Tikungan } \mathrm{Ke} \\
\text { Kanan dan } \\
\text { Menanjak }\end{array}$ & $\begin{array}{l}\text { Jalan sudah rata } \\
\text { dan halus }\end{array}$ & Peringatan tikungan ke kanan & $\begin{array}{l}\text { Marka } \\
\text { Membujur }\end{array}$ \\
\hline \multirow[t]{2}{*}{$132.0-136.6$} & Lurus & $\begin{array}{l}\text { Jalan tidak rata dan } \\
\text { bergelombang }\end{array}$ & $\begin{array}{l}\text { Batas minimum kecepatan } 60 \\
\mathrm{Km} / \mathrm{Jam} \& \text { batas maksimum } \\
\text { kecepatan } 100 \mathrm{Km} / \mathrm{Jam}\end{array}$ & $\begin{array}{l}\text { Marka } \\
\text { Membujur }\end{array}$ \\
\hline & & & Dilarang Berhenti & \\
\hline
\end{tabular}
dapat kita lihat pada tabel 2

Tabel 2 Tabel Karateristik Jalan 


\section{Pengujian Kruskall-Wallis}

Pengujian kruskall-wallis merupakan uji yang dilakukan jika data tidak normal dan akan dilakukan uji H. Data yang kita dapat akan menggunakan pengujian kruskall-wallis dengan program SPSS. Hasil dari pengujian kruskall-wallis dapat kita lihat pada tabel 3 dan 4 yang menjelaskan tentang hasil yang didapat untuk pengujian kruskall-wallis.

\begin{tabular}{|c|c|c|c|}
\hline BangunanPelengkap & & $\mathrm{N}$ & Mean Rank \\
\hline \multirow[t]{4}{*}{ ScoreTotal_Lurus } & 3 & 1 & 1.00 \\
\hline & 4 & 75 & 39.00 \\
\hline & 5 & 24 & 88.50 \\
\hline & Total & 100 & \\
\hline \multirow[t]{4}{*}{ ScoreTotal_Menurun } & 3 & 1 & 1.00 \\
\hline & 4 & 75 & 39.48 \\
\hline & 5 & 24 & 87.00 \\
\hline & Total & 100 & \\
\hline \multirow[t]{4}{*}{ ScoreTotal_Menanjak } & 3 & 1 & 1.00 \\
\hline & 4 & 75 & 39.48 \\
\hline & 5 & 24 & 87.00 \\
\hline & Total & 100 & \\
\hline \multirow[t]{4}{*}{$\overline{\text { ScoreTotal_Kiri }}$} & 3 & 1 & 1.00 \\
\hline & 4 & 75 & 39.48 \\
\hline & 5 & 24 & 87.00 \\
\hline & Total & 100 & \\
\hline \multirow[t]{4}{*}{ ScoreTotal_kanan } & 3 & 1 & 1.00 \\
\hline & 4 & 75 & 39.48 \\
\hline & 5 & 24 & 87.00 \\
\hline & Total & 100 & \\
\hline
\end{tabular}

Tabel 4 Test Statistics ${ }^{a, b}$

\begin{tabular}{|c|c|c|c|c|c|}
\hline & $\begin{array}{l}\text { ScoreTotal_L } \\
\text { urus }\end{array}$ & $\begin{array}{l}\text { ScoreTotal_ } \\
\text { Menurun }\end{array}$ & $\begin{array}{l}\text { ScoreTotal_ } \\
\text { Menanjak }\end{array}$ & $\begin{array}{l}\text { ScoreTotal } \\
\text { iri }\end{array}$ & $\begin{array}{l}\text { K ScoreTotal_k } \\
\text { anan }\end{array}$ \\
\hline Chi-Square & 58.177 & 54.179 & 54.268 & 54.191 & 54.179 \\
\hline$\overline{\mathrm{Df}}$ & 2 & 2 & 2 & 2 & 2 \\
\hline \multicolumn{6}{|l|}{ Asymp. Sig. } \\
\hline & .322 & .101 & .207 & .241 & .187 \\
\hline
\end{tabular}

Dari tabel diatas dapat kita lihat bahwa nilai mean rank menunjukkan peringkat rata-rata masing-masing presepsi pengemudi pada setiap bangunan pelengkap dengan geometrik yang berbeda. Pada tabel ranks dapat dilihat nilai mean rank menunjukan peringkat masing - masing presepsi pengemudi pada setiap bangunan pelengkap terhadap geometrik jalan yang berbeda. Mean rank terbesar terdapat pada jawaban 5, dapat kita ketahui bahwa banyak pengemudi yang menganggap bahwa bangunan pelengkap jalan untuk kondisi geometrik jalanan lurus sudah sangat baik. Dari tabel 4. terdapat perhitungan untuk masing - masing geometrik jalan.. Uji kruskall-wallis adalah uji yang dapat melihat signifikansi, untuk melihat pemberian pengaruh pada hipotesis yang sudah dibuat. Hipotesis untuk pengujian ini :

H0 adalah persepsi pengemudi terhadap bangunan pelengkap tidak berbeda secara signifikan.

H1 adalah persepsi pengemudi terhadap bangunan pelengkap jalan memang berbeda secara signifikan.

Nilai Asymp. Sig pada tabel 4.16 jika lebih besar dari 0,05 maka hipotesis H0 diterima dan hipotesis H1 ditolak, tetapi jika nilai Asymp. Sig lebih kecil dari 0,05 maka hipotesis H0 ditolak dan hipotesis H1 diterima.

Berdasarkan hasil wawancara pada rest area KM 166 arah Palimanan dan KM 101 arah Jakarta, walaupun pada kondisi sebenernya terdapat banyak kekurangan rambu pada jalan Tol Cipali, ternyata tidak terlalu mempengaruhi kenyamanan mengemudi bagi para pengguna jalan Tol Cipali. Hal ini menunjukkan bahwa sebenarnya pengemudi 
tidak sepenuhnya memperhatikan keberadaan rambu dan marka jalan pada setiap kondisi jalan sehingga mereka tidak menyadari adanya kekurangan rambu atau marka pada lokasi tertentu.

Berdasarkan Peraturan Menteri Nomor 13 Tahun 2004 pasal 39 ayat 2 sebelum mencapai bagian jalan yang kemungkinkan ada bahaya rambu peringatan diharuskan terpasang rambu peringatan paling sedikit 80 meter untuk jalan dengan kecepatan rencana $60 \mathrm{~km} / \mathrm{jam}$ hingga $80 \mathrm{~km} / \mathrm{jam}$ dan paling sedikit 100 meter untuk jalan dengan kecepatan rencana $60 \mathrm{~km} / \mathrm{jam}$ hingga $100 \mathrm{~km} / \mathrm{jam}$. Ketidakadaan rambu pada beberapa ruas daerah merupakan bentuk pelanggaran terhadap Peraturan Menteri Nomor 13 Tahun 2004. Namun hasil pengolahan data persepsi pengemudi terhadap rambu menunjukkan tingkat kepuasaan yang baik. Hal ini menandakan bahwa pengemudi tidak sepenuhnya memperhatikan keberadaan rambu atau marka jalan pada setiap kondisi jalan sehingga mereka tidak menyadari adanya kekurang rambu atau marka pada lokasi tertentu.

\section{Nilai angka ekivalen kecelakaan}

Nilai angka ekivalen kecelakaan berdasarkan nilai pembobotan tingkat keparahan korban kecelakaan MD: LB: LR = 12:3:3. Contoh perhitungan AEK di ruas Jalan Tol Cipali dapat dilihat pada tabel 5 data kecelakaan di jalan tol Cipali pada tahun 2017

Tabel 5 Data Kecelakaan Jalan Tol Cipali Sumber : PT Lintas Marga Sedaya

\begin{tabular}{|c|c|c|c|c|c|}
\hline \multirow[t]{2}{*}{ Nama Ruas Jalan } & \multirow[t]{2}{*}{$\mathrm{Km}$} & \multirow{2}{*}{$\begin{array}{l}\text { Total } \\
\text { Kecelakaan }\end{array}$} & \multicolumn{3}{|c|}{ Tingkat Keparahan } \\
\hline & & & MD & LB & LR \\
\hline Cikampek-Cikopo & $67.10-78.00$ & 79 & 17 & 41 & 55 \\
\hline Cikopo - Kalijati & $78.10-98.00$ & 152 & 38 & 102 & 132 \\
\hline Kalijati-Subang & $98.10-110.00$ & 177 & 42 & 91 & 151 \\
\hline Subang - Cikedung & $110.10-138.00$ & 267 & 73 & 181 & 223 \\
\hline Cikedung - Kertajati & $138.10-159.00$ & 69 & 11 & 28 & 51 \\
\hline Kertajati - Sumberjaya & $159.10-175.00$ & 44 & 9 & 18 & 31 \\
\hline Sumberjaya - Palimanan & $175.10-188.00$ & 45 & 7 & 21 & 33 \\
\hline
\end{tabular}

Subang - Cikedung dengan jumlah korban meninggal dunia 73 orang, jumlah korban luka berat 181, dan jumlah korban luka ringan 223 orang. Nilai angka ekivalen dihitung sebagai berikut:

$\mathrm{AEK}=12 \mathrm{xMD}+3 \mathrm{xLB}+3 \mathrm{xLR}$

$\mathrm{AEK}=(12 * 73)+(3 * 181)+(3 * 223)=2088$

Jumlah angka ekivalen kecelakaan (m) di ruas Subang - Cikedung adalah 2088. Setelah semua nilai AEK dihitung maka langkah selanjutnya yaitu mencari nilai rata-rata kecelakaan $(\lambda)$ yang diperoleh dari jumlah nilai AEK dibagi dengan jumlah ruas jalan. Nilai rata-rata kecelakaan $(\lambda)$ pada tahun 2017 sebesar 834.

Perhitungan nilai batas dilakukan untuk mengetahui batas tingkat kerawanan kecelakaan tiap ruas jalan, dimana setiap ruas jalan memiliki batas tingkat kerawanan kecelakaan yang berbeda-beda. Perhitungan ini menjadi acuan untuk menentukan ruas jalan yang termasuk daerah rawan kecelakaan di ruas jalan tol Cipali. Contoh perhitungan nilai UCL (Upper Control Limit) pada ruas jalan Subang - Cikedung dengan data angka kecelakaan rata-rata $(\lambda)=$ 834; nilai faktor probabilitas $(\Psi)=2,576$, dan jumlah angka ekivalen kecelakaan $(\mathrm{m})=2436$. Diperoleh nilai upper control limit ruas jalan Subang - Cikedung $=917.2359167$. Nilai batas kontrol atas diperoleh dengan memasukkan nilai rata-rata angka ekivalen kecelakaan pada tahun 2017 sebesar 883.7143 ke Persamaan 3 dan diperoleh nilai $\mathrm{BKA}=870.2904905$. Hasil analisis nilai UCL dan BKA menggunakan contoh perhitungan diatas untuk 7 ruas jalan pada tahun 2017 selengkapnya ditunjukkan pada Tabel 6. 
Tabel 6 Nilai angka ekivalen kecelakaan, upper control limit dan batas kontrol

\begin{tabular}{|c|c|c|c|c|c|c|}
\hline \multirow{2}{*}{ Nama Ruas Jalan } & \multirow{2}{*}{$\mathrm{Km}$} & \multicolumn{3}{|c|}{ Angka Ekivalen Kecelakaan } & \multirow{2}{*}{ UCL } & \multirow{2}{*}{ BKA } \\
\hline & & $12 \times M D$ & $3 \times(L B+L R)$ & Total & & \\
\hline Cikampek - Cikopo & $67.10-78.00$ & 204 & 288 & 492 & 874.4275367 & 870.2905 \\
\hline Cikopo - Kalijati & $78.10-98.00$ & 456 & 702 & 1158 & 895.991593 & 870.2905 \\
\hline Kalijati - Subang & $98.10-110.00$ & 504 & 726 & 1230 & 897.8889362 & 870.2905 \\
\hline Subang - Cikedung & $\begin{array}{c}110.10- \\
138.00\end{array}$ & 876 & 1212 & 2088 & 917.2359167 & 870.2905 \\
\hline Cikedung - Kertajati & $\begin{array}{l}138.10- \\
159.00\end{array}$ & 132 & 237 & 369 & 869.0278048 & 870.2905 \\
\hline Kertajati - Sumberjaya & $\begin{array}{c}159.10- \\
175.00\end{array}$ & 108 & 147 & 255 & 863.15289 & 870.2905 \\
\hline Sumberjaya - Palimanan & $\begin{array}{c}175.10- \\
188.00\end{array}$ & 84 & 162 & 246 & 862.6386122 & 870.2905 \\
\hline
\end{tabular}

\section{Pembahasan}

Dari analisis dan perhitungan yang dilakukan maka diperoleh hasil sebagai berikut :

1. Dari data responden yang telah dianalisis maka diperoleh bahwa nilai mean rank menunjukkan peringkat rata-rata masing-masing presepsi pengemudi pada setiap bangunan pelengkap dengan geometrik yang berbeda. Pada tabel ranks dapat dilihat nilai mean rank menunjukan peringkat masing - masing presepsi pengemudi pada setiap bangunan pelengkap terhadap geometrik jalan yang berbeda. Mean rank terbesar terdapat pada jawaban 5, dapat kita ketahui bahwa banyak pengemudi yang menganggap bahwa bangunan pelengkap jalan untuk kondisi geometrik jalanan lurus sudah sangat baik. Uji kruskall-wallis adalah uji yang dapat melihat signifikansi, untuk melihat pemberian pengaruh pada hipotesis yang sudah dibuat. Dan didapat bahwa hasil dari presepsi pengemudi terhadap bangunan pelengkap tidak berbeda secara signifikan.

2. Dari hasil pengamatan walaupun pada kondisi sebenernya terdapat banyak kekurangan rambu dan perkerasan jalan banyak yang kurang baik pada jalan Tol Cipali, ternyata tidak terlalu mempengaruhi kenyamanan mengemudi bagi para pengguna jalan Tol Cipali. Hal ini menunjukkan bahwa sebenarnya pengemudi tidak sepenuhnya memperhatikan keberadaan rambu dan marka jalan pada setiap kondisi jalan sehingga mereka tidak menyadari adanya kekurangan rambu atau marka pada lokasi tertentu. Dapat dilihat bahwa kondisi perkerasan jalan belum sepenuhnya rata dan bergelombang pada Km85+20 - Km86+00 dan Km132+00 - Km136+60, tidak adanya rambu peringatan untuk memperingati pengemudi bahwa tidak ada rambu menanjak pada Km104+60 - Km105+00, dan lokasi pada jalan Tol Cipali yang tidak memiliki rambu dijalan arah Cikopo kearah Palimanan.

3. Dari hasil analisis data kecelakaan lalu lintas, dapat disimpulkan lokasi rawan kecelakaan lalu lintas diperoleh untuk tahun 2017 adalah terdapat tiga ruas jalan yaitu ruas Cikopo - Kalijati (Km78.10 - Km98.10), Kalijati - Subang (Km98.10 - Km110.00), dan Subang - Cikedung (Km110.00 - Km138.00). Itu menunjukkan bahwa ketiga ruas tersebut merupakan daerah rawan kecelakaan pada jalan tol Cipali.

\section{KESIMPULAN DAN SARAN}

Adapun kesimpulan dari hasil analisis dalam penelitian ini yaitu:

1. Dari hasil oberservasi secara langsung, kondisi eksisting geometrik, bangunan pelengkap, dan perkerasaan sudah cukup baik. Namun terdapat kekurangan rambu dan jalan yang tidak halus dalam perkerasaan di beberapa ruas jalan tol Cipali, akan tetapi tidak mempengaruhi kenyamanan pengemudi untuk pengguna jalan tol Cipali menurut wawancara pada saat penyebaran kusioner berlangsung.

2. Dari hasil observasi langsung, dapat disimpulkan bahwa ada beberapa ruas jalan Tol Cipali yang tidak ada rambu sama sekali pada KM 75+40 - KM 76+20, KM 80+00 - KM 80+80, KM 91+20 - KM 93+00.

3. Dari hasil observasi langsung, dapat juga disimpulkan bahwa pada ruas KM132+00 - KM136+60 masih terdapat banyak kondisi jalan yang perkerasannya tidak rata dan halus.

4. Dari hasil analisis data kecelakaan lalu lintas, dapat disimpulkan ruas rawan kecelakaan lalu lintas diperoleh untuk tahun 2017 adalah ruas Cikopo - Kalijati (KM78.10 - KM98.10), Kalijati - Subang (KM98.10 - KM110.00), dan Subang - Cikedung (KM110.00 - KM138.00). Itu menunjukkan bahwa ketiga ruas tersebut merupakan daerah rawan kecelakaan pada jalan tol Cipali.

5. Dari hasil perhitungan menggunakan SPSS dengan cara kruskall-wallis maka dapat disimpulkan bahwa persepsi pengemudi terhadap bangunan pelengkap dan kondisi perkerasan jalan Tol Cipali pada saat jalan lurus, menurun, menanjak, menikung ke kiri, dan menikung ke kanan sudah cukup baik dengan mean rank sebesar 87.00 untuk 
jawaban sangat setuju (5), 39.50 untuk jawaban setuju (4), dan 1.00 untuk jawaban kurang setuju (3). Sedangkan tidak ada responden yang menjawab dengan jawaban tidak setuju dan sangat tidak setuju. Akan tetapi hasil dari persepsi pengemudi tersebut tidak banyak memberikan pengaruh karena perbedaannya tidak signifikan yang berarti pengemudi tidak terlalu menghiraukan, karena perbedaan tidak signifikan maka hipotesis H0 (Persepsi pengemudi terhadap kondisi eksisting bangunan pelengkap jalan dan kondisi perkerasan jalan pada tol Cipali tidak berbeda secara signifikan) diterima dan hipotesis H1 (Persepsi pengemudi terhadap kondisi eksisting bangunan pelengkap jalan dan kondisi perkerasan jalan pada jalan Tol Cipali memang berbeda secara signifikan) ditolak.

\section{Saran}

1. Pada saat mengendarai kendaraan untuk pengamatan langsung lebih baik mengendalikan kecepatan yang konstan.

2. Data responden atau kusioner diperbanyak.

3. Pada saat menggunakan kamera lebih baik mengetahui kapasitas memori untuk merekam dan memiliki kualitas yang cukup baik untuk merekam gambar bangunan pelengkap.

\section{DAFTAR PUSTAKA}

Departemen Pekerjaan Umum Direktorat Jenderal Bina Marga, (1997), Tata Cara Perencanaan Geometrik Jalan Antar Kota, Jakarta

Ditjen Bina Marga, (2007), Modul Pelatihan Inspeksi Keselamatan Jalan (IKJ) dalam Penyelenggaraan Jalan Berkeselamatan, Departemen Pekerjaan Umum, Jakarta

Mulyono, A.T., Berlian, K., Gunawan, H.E., (2009), Penyusunan Model Audit Defisiensi Keselamatan Infrastruktur Jalan untuk Mengurangi Potensi Terjadinya Kecelakaan Berkendaraan, Laporan Hibah Kompetitif Penelitian sesuai Prioritas Nasional Batch II, LPPM UGM, Yogyakarta.

Soemitro and Aryani, R.A. (2005). Accident Analysis Assessment to the Accident Influence Factors on Traffic Safety Improvement (case: PalangkarayaTangkiling National Road). Proceedings of the Eastern Asia Society for Transportation Studies (EASTS) 5, pp. 2091-2105.

Sugiyanto, G., Mulyono, B. dan Santi, M.Y. (2014). "Karakteristik Kecelakaan Lalu Lintas dan Lokasi Black Spot di Kabupaten Cilacap”, Jurnal Teknik Sipil Universitas Atma Jaya Yogyakarta, Volume 12, No. 4, April 2014, hal. 259- 266. 